\title{
COMMENTARY
}

\section{Rethinking the Pharmacy Workforce Crisis by Exploring Unconventional and Emerging Career Pathways and Training}

\author{
Sharon K. Park, PharmD, MEd, ${ }^{a}$ Kimberly K. Daugherty, PharmD, PhD, ${ }^{\mathrm{b}}$ Srikanth Kolluru, MS Pharm, PhD, ${ }^{\mathrm{c}}$ \\ Lisa Lebovitz, JD, MS, ${ }^{\mathrm{d}}$ Simi Gunaseelan, PhD, ${ }^{\mathrm{e}}$ Beth K. Janetski, PhD, ${ }^{\mathrm{f}}$ Rosalyn Padiyara Vellurattil, \\ PharmD, ${ }^{\mathrm{g}}$ Justine Gortney, PharmD ${ }^{\mathrm{h}}$
}

${ }^{a}$ Notre Dame of Maryland University, School of Pharmacy, Baltimore, Maryland

${ }^{\mathrm{b}}$ Sullivan University, College of Pharmacy and Health Sciences, Louisville, Kentucky

${ }^{\mathrm{c}}$ Keck Graduate Institute, School of Pharmacy and Health Sciences, Claremont, California

${ }^{\mathrm{d}}$ University of Maryland, School of Pharmacy, Baltimore, Maryland

${ }^{\mathrm{e}}$ Texas A\&M University, Irma Lerma Rangel College of Pharmacy, Kingsville, Texas

${ }^{\mathrm{f}}$ University of Wisconsin-Madison, Madison, Wisconsin

${ }^{\mathrm{g}}$ University of Illinois at Chicago, College of Pharmacy, Chicago, Illinois

${ }^{\mathrm{h}}$ Wayne State University, Eugene Applebaum College of Pharmacy and Health Sciences, Detroit, Michigan

Corresponding Author: Sharon K. Park, Notre Dame of Maryland University, School of Pharmacy, 4701 North Charles St., Baltimore, MD 21210. Tel: 410-532-5061. Email: spark@ ndm.edu

Submitted June 15, 2021; accepted September 27, 2021; ePublished October 2021

Pharmacy programs face a challenge in ensuring that all graduates obtain jobs that fulfill their goals and ambitions as pharmacists, given the limited availability of conventional positions in the workforce. Thus, it is imperative to explore and discuss the availability and needs of the positions that are unconventional but promising. To achieve this exploration, it is important to (1) recognize technical and nontechnical skill sets that pharmacy graduates possess at graduation, (2) identify unique pathways to help students explore job alternatives, and (3) educate faculty and students of employment opportunities beyond the traditional setting if desired or necessary. Students must become aware of the opportunities existing in both conventional (pharmacist clinician) and unconventional (pharmacist innovator) pharmacy careers and be able to articulate the translational skills from their training. Pharmacy programs and faculty can better support students by fostering the development and marketing of their skills.

Keywords: graduates, pharmacy workforce, innovation, entrepreneurship

\section{INTRODUCTION}

Pharmacists offer a broad set of technical skills and expertise that optimize patient care, mitigate health disparities, and add value to research and decision-making. As thousands of graduates compete for jobs every year with large amounts of debt, pharmacy educators must do more to prepare students to seek out positions that may not be traditional or familiar, articulate their transferable skills such as an innovative mindset and a team focus, and promote the benefits of utilizing medication expertise for diverse perspective. The questions we should ask ourselves are: Are we educated enough about roles that did not exist when we were training? Are we "preaching to the choir" about community and hospital positions but not other opportunities which graduates can create and develop with their pharmacist skills? With market demands, societal views on consumerism, and expectations of health care change, being resistant to new opportunities or ignoring the currently limited job market may put our graduates at risk of not meeting their full potential. Given these questions and issues, pharmacy educators must articulate a new vision for what and how pharmacists function and be ready to discuss the opportunities beyond the perceived limits in creativity, skills development, and societal contribution. We must educate ourselves about how to identify potential alternative and unconventional roles and educate our graduates on how to successfully secure those opportunities.

To begin this discussion, it is important to first define the traditionally known pharmacist positions (conventional roles referred to herein as "pharmacist clinician") as those in community, health care institutions, and ambulatory care settings in which pharmacists provide direct patient care. Unconventional positions ("pharmacist innovator") are those not included in the conventional positions defined above. In this commentary, we highlight what skills student pharmacists 
are acquiring through their PharmD programs that could open doors for alternative roles. Then, we discuss and reflect on how faculty and programs could better support graduates for the current workforce climate and new opportunities for gainful employment.

\section{Recognizing Diverse and Transferable Pharmacist Skills}

Pharmacists bring much more to the table than patient-focused medication management expertise. Although it is not widely recognized or discussed among pharmacy educators, programs already train students for employment in a broad range of unconventional positions through the development of the nontechnical skills (soft skills) that are part of many curricular and co-curricular activities. While there is no good definition of soft skills, they are generally defined as nontechnical skills that may be difficult to measure but define a person as a mature, responsible, cognizant, and creative human being. Some of these skills are contained in the ACPE 2016 Standards 3 and 4 -- problem-solving, interprofessional collaboration, cultural sensitivity, communication, self-awareness, leadership, and innovation and entrepreneurship. ${ }^{1}$ These skills are transferable skills needed to make one a good leader and conflict manager, while also being essential to help advance one's career. They align with the most sought-after skills by employers of many professions and include creativity, persuasion, collaboration, adaptability, and emotional intelligence. ${ }^{2}$ Studies have found that some of the most useful soft skills are a positive attitude, communication, teamwork, and strong work ethics. ${ }^{3}$

A PharmD education provides students with many opportunities in which they can develop and actively demonstrate these skills, while their creativity and adaptability allow them to articulate how these transferable skills apply to different contexts. The soft and transferable skills provide keywords for PharmD graduates to search for in unconventional pharmacy job postings and make them well suited for many of the new areas of pharmacy and health care that may not have been considered avenues for pharmacists in the past. Graduates who look beyond the degree requirement line of a job posting will find interesting, dynamic, and fulfilling work that uses their entire skill set. Recognizing and articulating these skills can help graduates in searching for both conventional and unconventional career paths. Students who do not readily find a role in a typical community or hospital pharmacy setting may discover a perfect fit in another health-related or marketplace setting that values their transferable skills and attain job satisfaction. This leap would require the students to think outside the box to create their career paths, beyond the limited options presented to them upon graduation.

\section{Uncovering Underexplored and Emerging Career Paths}

Several areas of conventional pharmacy roles continue to be underexplored by pharmacists entering the workforce and are worth pursuing, based on position forecasting. As a prime example of forging the path ahead, ambulatory care is a sector of pharmacy practice that has steadily grown over the past 20 years, and around 15,400 pharmacists currently work in these settings. ${ }^{4}$ This role is expected to grow as much as $20 \%$ to 18,600 jobs by $2029 .{ }^{4}$ Another area of growth is the provision of pharmacy services online; this newer role is projected to grow from the current 5,500 jobs to 7,100 jobs (31\%) by 2029. Recent changes in non-urgent health care to virtual delivery is a golden opportunity for pharmacists to take on a broader role in telehealth or telemedicine. ${ }^{5}$

The pharmaceutical industry continues to expand, and pharmacy graduates are well-positioned for employment in this venue with their research and clinical backgrounds. ${ }^{6}$ Currently, 79 pharmaceutical companies offer fellowship programs, according to the 2019-20 fellowship report. ${ }^{7}$ Medical affairs, clinical research and development, and regulatory affairs are the top three areas for fellowships. Fellowship programs increased by $111 \%$ over the last six years and other fellowship areas that are currently being offered include pharmacovigilance, medical information, market access, clinical supply, drug safety, clinical development, and marketing. Industry Pharmacists Organization helps advance pharmacists' professional careers by advocating for their role in drug development and medication use. ${ }^{7}$

The COVID pandemic and the opioid crisis have also opened doors for pharmacists in areas such as public health, substance abuse treatment, and immunization. Other positions that graduates could consider are in more unconventional areas where both the technical and soft skill sets are highly relevant: non-profit association leadership or management, academia, federal government agencies such as Federal Emergency Management Agency (FEMA) or Center for Medicare and Medicaid Services, state and regional health organizations such as departments of health or public service, research in academia or the biotechnology industry, supply chain and distribution management, specialty pharmacy distribution and management, managed care such as health management organizations, and quality improvement in health systems or pharmaceutical companies (Table). 


\section{Implementing Strategies to Support Graduates in Developing Skills}

While PharmD graduates possess skills that are both universal and transferable to the health care sector and the global marketplace, a shortcoming of PharmD programs is the education of students on self-advocacy or how to (1) integrate their strong clinical backgrounds and transferable skills into tomorrow's practice models, and (2) market the skills they have and become aware of long-term opportunities. Schools and colleges of pharmacy (S/COPs) can leverage co-curriculum and interprofessional education opportunities to help students see the wider transferability of their skills into unconventional practice models and areas of employment. To help students see the value of co-curricular activities, S/COPs need to move beyond unstructured activities which comprise many co-curricular plans currently. ${ }^{8}$ Pharmacy graduates would benefit from intentional incorporation of how co-curricular activities can prepare them for positions as medication experts outside of patient care. In addition, structured interprofessional education opportunities in innovative practice models need to be explored to help students in all professions learn how to become innovators in their professions.

Another area for student development is the innovative use of technology. In this era of digital transformation, how can new graduates market and promote their skills as the medication expert in ways that make pharmacists accessible to patients outside the traditional hospital, community, or clinic setting? Technological inventions (eg, medication dispenser, 3D printing), store-to-door convenience (eg, Amazon Pharmacy), social media (eg, "influencer"), artificial intelligence (eg, precision medicine), telemedicine (eg, home care), and digital disruption (eg, app creation) are some of the changes we have experienced yet not taught our graduates. ${ }^{9-12}$ However, cultivating human connection in a digital world is vital, and how this is taught and delivered in pharmacy curricula needs focus. Incorporating communication via social media into the curriculum to focus on content creation, podcast production, designing effective websites, app creation, and ethics for digital patient care must be considered. These basic technical skills can help graduates create, innovate, and influence online communities that have a broader reach than typical pharmacy settings. By demonstrating their value as health care professionals on online platforms, graduates can contribute to practice transformation. ${ }^{13}$ In addition to furthering team development and technology skills, schools should address specialized didactic content that may further enhance students' unique skill set. This content could take the shape of certificates and dual-degree programs ${ }^{14}$ Potential curricular topics include personalized medicine and pharmacogenetics, and patient education related to them. ${ }^{15}$ Knowledge gained through certificates and dual degree programs also brings awareness about unconventional careers to students early in their education. ${ }^{16}$

\section{Enlisting Faculty as Messengers and Role Models}

To help students learn how to market more than their patient care skills, faculty members must discuss the unique skill sets that their student pharmacists are developing and how students can find jobs in unconventional areas with these skills. Faculty should become more aware of what is taught in their curricula and co-curricula, and how that can translate to conventional and unconventional workplaces for pharmacy graduates. Faculty should serve as role-models and mentors on how to be innovative and entrepreneurial; guide them on how to read job descriptions and market themselves for jobs that are not necessarily looking for a PharmD but could become rewarding careers.

For faculty to serve as messengers and role models for students in this regard, S/COPs should dedicate resources to develop faculty to raise awareness for new and unconventional areas of practice, and minimize their perceptions, biases, or judgments stemming from the lack of knowledge and awareness about such career paths. Brown and colleagues ${ }^{17}$ evaluated faculty perceptions of postgraduate training and found greater awareness of community-based (95\%) and hospital-based residency programs (94\%) than community-based fellowships (59\%) and independent pharmacy ownership residencies (31\%). Respondents showed preferential bias toward hospital-based pharmacy residencies, with $83 \%$ rating them "very valuable" compared to community-based residencies (59\%) and fellowships $(61 \%)$. In a changing workforce, faculty need to consider their own biases and messaging to students. Faculty should learn about residency programs that have a practice expansion focus and engage with alumni that are in unconventional roles. Connecting with a campus career development center or teaching students to effectively use platforms such as LinkedIn or job search applications may be beneficial. Another strategy is for schools to enhance an alumni mentorship program to expose students and faculty to pioneering innovators and unconventional positions in pharmacy. ${ }^{18}$

Creating opportunities for students to engage in professional mentorship and leadership development is also beneficial for their career preparation. A unique mentorship program for PharmD students with highly effective external pharmacy leaders can help prepare student pharmacists early on with individualized career success. ${ }^{19}$ One such comprehensive longitudinal hands-on-mentoring program launched at the University of Wisconsin-Madison developed an innovative pharmacy leadership non-credit certificate and mentor (LCM) program that cultivates student's leadership 
skills through a course, targeted activities, specific self-reflection questions, community service opportunities, and leadership conference opportunities, along with a mentoring relationship that connects students and practicing pharmacist mentors. Most of the LCM program takes place outside the classroom, so students are building their skills on their own time. ${ }^{20}$ Overall, the goal of these professional development opportunities is to help students envision themselves in aspirational positions and cultivate their mindset to see beyond the perceived limits. They can become pharmacist clinicians or innovators, or both.

\section{CONCLUSION}

Given the current job market, schools must provide opportunities for students to explore conventional and unconventional but emerging pharmacy careers. Pharmacy graduates need to articulate and self-promote their skill sets to potential employers beyond patient care. It is imperative that both S/COPs and faculty look for ways to help students learn to further develop and market their transferable and in-demand skills, and to forge ahead for future career paths in pharmacy.

\section{REFERENCES}

1. Accreditation Council for Pharmacy Education. Accreditation standards and key elements for the professional program in pharmacy leading to the Doctor of Pharmacy degree, 2015. https://www.acpeaccredit.org/pdf/Standards2016FINAL.pdf. Accessed May 18, 2021.

2. Gavin M. 10 Important business skills every professional needs. Harvard Business School Online. https://online.hbs.edu/blog/post/business-skills-every-professional-needs. Updated June 14, 2019. Accessed May 29, 2021.

3. Tripathy M. Significance of soft skills in career development. In: Fahed-Sreih J, eds. Career Development and Job Satisfaction. India. 2020 doi:10.5772/intechopen.89935. Accessed June 14, 2021.

4. Arya V, Bakken B, Doucette WR, Gaither CA, Kreling DH, Mott DA et al. National pharmacist's workforce study 2019. American Association of Colleges of Pharmacy website, 2020. https://www.aacp.org/sites/default/files/2020-03/2019_NPWS_Final_Report.pdf. Accessed June 14, 2021.

5. Le T, Toscani M, Colaizzi. Telepharmacy: a new paradigm for our profession. J Pharm Pract 2020; 33(2):176-82. doi: 10.1177/0897190018791060.

6. Grand View Research. Pharmaceutical manufacturing market size, share, and trends analysis report by drug development type, by formulation, by route of administration, by therapy area, by prescription, by age group, and segment forecasts, 2020-2027. 2020. https://www.grandviewresearch.com/industry-analysis/pharmaceuticalmanufacturing-market Accessed June 14, 2021.

7. Alexander JG, Campo G, Dadhich P, Ruthsatz O, Szeto AH. Analysis of 2019-2020 Pharm.D. industry fellowships. https://www.industrypharmacist.org/resources/d281ebbbdeb612d374a24ab785854639.pdf. Accessed June 14, 2021.

8. Maerten-Rivera JL, Chen AMH, Augustine J, et al. Co-curriculum implementation and assessment in accredited Doctor of Pharmacy programs. Am J Pharm Educ. 2020;84(3):7569.

9. Pharmacy is Right For Me. Novel pharmacy practice settings. 2020. https://pharmacyforme.org/novel-practicesettings/. Accessed August 20, 2021.

10. TED Conferences, LLC. The pharmacy of the future? Personalized pills, 3D printed at home. 2018. https://www.ted.com/talks/daniel kraft the pharmacy of the future personalized pills $3 \mathrm{~d}$ printed at home?la nguage $=$ en. Accessed August 20, 2021.

11. University of Florida. Artificial intelligence - empowering the future of pharmacy. https://pharmacy.ufl.edu/research/artificial-intelligence-empowering-the-future-of-pharmacy/ Accessed August 20, 2021.

12. Huynh G, Pham T, Yu C, Vuong M, Tso L. The emerging role of pharmacists as social media influencers. Pharmacy Times. 2021. https://www.pharmacytimes.com/view/the-emerging-role-of-pharmacists-as-socialmedia-influencers. Accessed August 20, 2021.

13. Vogenberg FR. and Santilli J. Healthcare trends for 2018. Am Health Drug Benefits. 2018;11(1):48-55.

14. Vuernick EL, Josefiak KF, Spooner JJ, Kennedy D. Non-doctoral and dual degree offerings in US Pharmacy Schools. Am J Pharm Educ. 2019;83(7):6917.

15. Kennedy MJ. Personalized medicines - are pharmacists ready for the challenge? Integr Pharm Res Pract. 2018;7:113-123. 
16. Berlie HD, Janke KK, Garwood CL. Cultivating a vibrant and thriving elective curriculum in pharmacy schools. Am J Pharm Educ. 2020;84(4):7802.

17. Brown A, Hughes TD, Robinson JM, Prothero JB, Ferrari SP. Faculty knowledge, attitudes, and practices toward community-based pharmacy residencies and fellowships. J Am Coll Clin Pharm. 2021;4:819-826.

18. Kalata LR, Abate MA. A mentor-based portfolio program to evaluate pharmacy students' self-assessment skills. Am J Pharm Educ. 2013;77(4):81.

19. Raub JN, Fiorvento A, Franckowiak TM, Wood T, Gortney JS. Implementing and sustaining a mentorship program at a college of pharmacy: The keys to successful mentorship. Curr Pharm Teach Learn. 2017;9(2):296301.

20. Ginder-Vogel K. New school of pharmacy leadership certificate and mentor program prepares student pharmacists for career success. 2017; https://pharmacy.wisc.edu/new-leadership-certificate-mentor-programprepares-student-pharmacists-for-career-success/. Accessed June 14, 2021.

Table. Examples of Pharmacist Innovator Positions for Pharmacy Graduates

Practice Category

Ambulatory Care

Population-focused clinics

Immunization

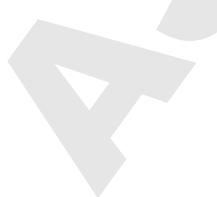

Impizition

Pain management and palliative care

Substance use disorder

Referral service

Telepharmacy

Triage/referral center

Urgent care centers

Medication therapy management

Medication counseling

Medication order review and approval
Consulting

Contract research and education

\section{Clinical trial management \\ Literature evaluation \\ Continuing education \\ Content and document review}

Patient-oriented coaching and medication management for holistic health care

Wellness coaching and management 
Academia

Medication management

Medical writing

Toxicology

Patient counseling

Public health policy
Curriculum and assessment

Continuing education

Instructional design and technology

Diversity, equity, and inclusion

Coaching and mentoring of faculty and students

Pharmacogenetics testing and interpretation

Contracted writing for pharmaceutical company's

clinical trial information

Continuing education materials

Ghostwriting

Poison control center

Emergency department contracts

Herbal/supplement review and counseling

Medication-related pamphlets or education materials

Online educational media resources

Federal and state government

Law offices

Pharmaceutical companies

\section{Entrepreneurism}

\section{Human resources management}

Managed care

Venture capital

Administration and legislation

Government
Pharmacy technician training and certification

Relief pharmacist service

Emergency staffing and coordination

Health and insurance management

Compounding and compliance

Veterinary

Complementary and alternative medicine

Wellness management

Formulary management

Resources management

Specialty pharmacy management

Evidence review and consultation

Drug pipeline analysis

Target drug candidate research

Global market trend analysis

Business intelligence for pharmaceutical products

Federal and state Medicare and Medicaid services State board of pharmacy

Behavioral health

Disabilities

Formulary management

Emergency preparedness

Federal, state, and local offices of emergency medical care

Disaster preparedness and product acquisition and distribution

Primary care
Department of Veterans Affairs Indian Health Services 
Office of Inmate Health and Clinical Services

Public health

U.S. Department of Health and Human Services including FDA, NIH, AHRQ, SAMHSA

State departments of health

\begin{tabular}{|c|c|c|}
\hline \multirow[t]{3}{*}{$\begin{array}{l}\text { Informatics and } \\
\text { technology }\end{array}$} & Informatics consulting & $\begin{array}{l}\text { Clinical informatics } \\
\text { EMR, EHR application expertise } \\
\text { Best practices policy expert } \\
\text { Pharmacogenomics implementation }\end{array}$ \\
\hline & Mobile-integrated health & $\begin{array}{l}\text { Product review } \\
\text { Content analysis } \\
\text { User experience analysis } \\
\text { Education and referral }\end{array}$ \\
\hline & Research and development & $\begin{array}{l}\text { Product development and testing } \\
\text { Technology validation }\end{array}$ \\
\hline \multirow[t]{3}{*}{$\begin{array}{l}\text { Nonprofit association } \\
\text { management }\end{array}$} & Healthcare organizations & $\begin{array}{l}\text { Oversight of medication acquisition and } \\
\text { distribution in global organizations (eg, WHO) } \\
\text { Public health data analysis }\end{array}$ \\
\hline & Patient advocacy organizations & $\begin{array}{l}\text { Rare disease and orphan drug expertise } \\
\text { Product review and analysis } \\
\text { Blogging and writing for education and counseling }\end{array}$ \\
\hline & Pharmacy organizations & $\begin{array}{l}\text { Association management } \\
\text { Continuing education } \\
\text { Market and trends analysis }\end{array}$ \\
\hline \multirow[t]{5}{*}{$\begin{array}{l}\text { Pharmaceutical / } \\
\text { healthcare maintenance } \\
\text { organization / pharmacy } \\
\text { benefits management / } \\
\text { for-profit industry }\end{array}$} & Global Health & $\begin{array}{l}\text { Market research } \\
\text { Consumer/user experience research } \\
\text { Business analytics } \\
\text { Global market liaison } \\
\text { Clinical trials management }\end{array}$ \\
\hline & Marketing and communication & $\begin{array}{l}\text { Product promotion and marketing } \\
\text { Consumer and patient education }\end{array}$ \\
\hline & $\begin{array}{l}\text { Medical affairs / drug } \\
\text { information }\end{array}$ & $\begin{array}{l}\text { Literature reviews } \\
\text { Reimbursement policy } \\
\text { Formulary management } \\
\text { Medication-use policy } \\
\text { Education materials } \\
\text { Medical science liaison }\end{array}$ \\
\hline & Pharmacoeconomics & $\begin{array}{l}\text { Drug utilization reviews } \\
\text { Cost-effectiveness analyses } \\
\text { Applied pharmacoeconomics }\end{array}$ \\
\hline & $\begin{array}{l}\text { Research intelligence and } \\
\text { support }\end{array}$ & $\begin{array}{l}\text { Evidence-based content generation } \\
\text { Applied and translational research }\end{array}$ \\
\hline $\begin{array}{l}\text { Production and } \\
\text { manufacturing }\end{array}$ & Compounding & $\begin{array}{l}\text { Pediatric and special population service } \\
\text { Veterinary pharmacy } \\
\text { Infusion services }\end{array}$ \\
\hline
\end{tabular}


I.V. fluid manufacturing and distribution

Medical equipment and devices Patient-oriented services

Customizable equipment and medical devices

Designing and testing

Promotion and marketing

\begin{tabular}{lll}
\hline $\begin{array}{l}\text { Social media / } \\
\text { Journalism }\end{array}$ & $\begin{array}{l}\text { Pharmacy and health } \\
\text { "Influencer"/content creator }\end{array}$ & $\begin{array}{l}\text { "Blogging" and " } \\
\text { Podcasting } \\
\text { Product and cont }\end{array}$ \\
& Medical journalism & $\begin{array}{l}\text { Content creation } \\
\text { Medical writing } \\
\text { Ghostwriting }\end{array}$ \\
& Online reporting
\end{tabular}

AHRQ = Agency for Healthcare Research and Quality; EHR = electronic health record; EMR = electronic medical record; FDA $=$ U.S. Food and Drug Administration; HIV = human immunodeficiency virus; NIH = National Institutes of Health; SAMHSA = Substance Abuse and Mental Health Services; $\mathrm{WHO}=$ World Health Organization 
Figure. Diverse Opportunities for Pharmacist Innovators

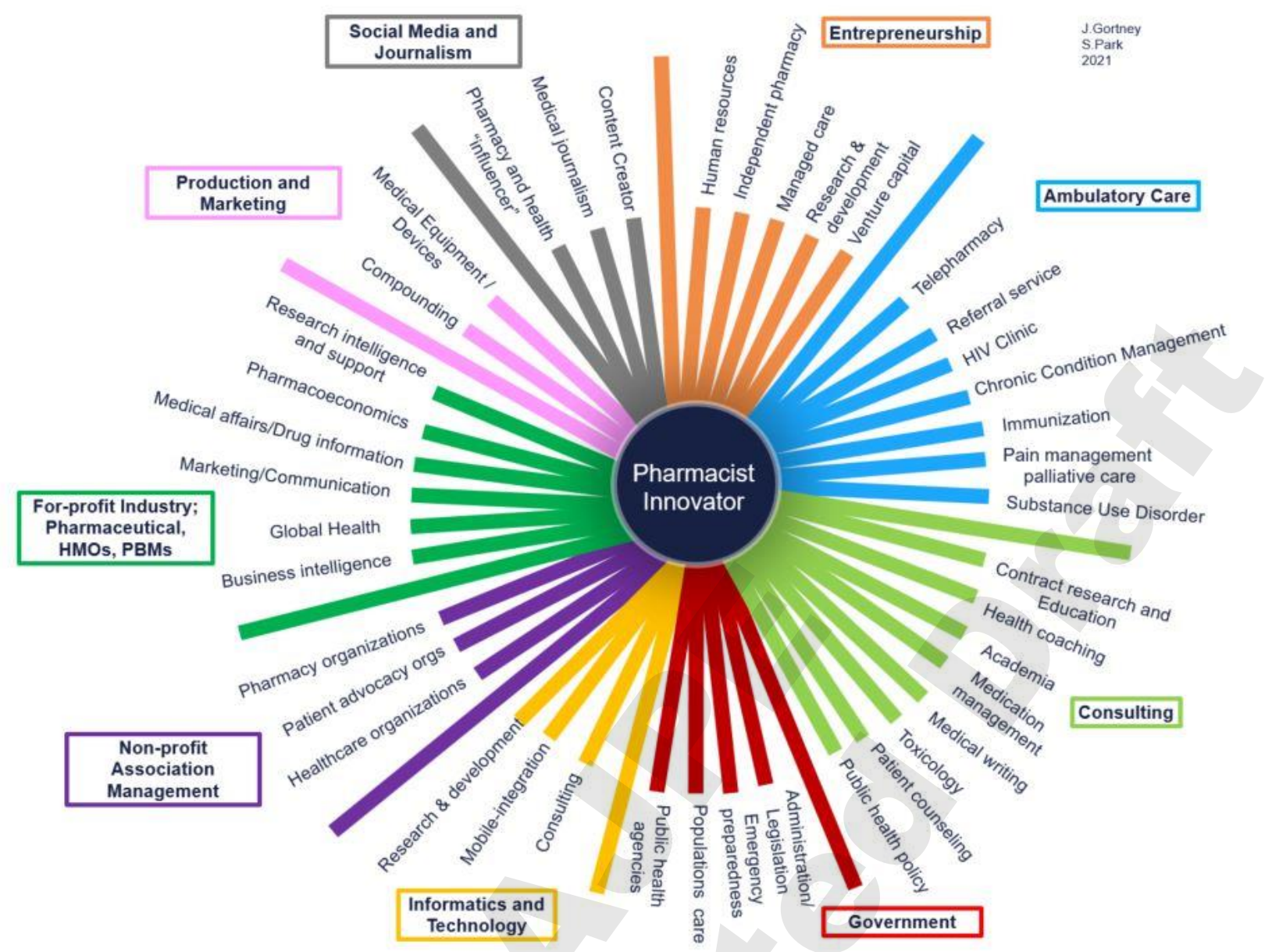

